\title{
About the mechanical ventilator as a shared resource for the Covid-19 pandemic
}

\section{Acerca del ventilador mecánico como recurso divisible ante la pandemia de COVID-19}

\author{
Jorge A. Castañón-González, * Luis A. Gorordo-Delsol, Jessica Garduño-López and \\ Marcos A. Amezcua-Gutiérrez \\ Intensive Care and Critical Medicine Unit, Hospital Juárez de México, Secretaría de Salud, Mexico City, Mexico
}

We read with interest the article "Mechanical ventilator as a shared resource for the Covid-19 pandemic" by doctor Gilberto Vázquez-de Anda et al., ${ }^{1}$ which we consider topical and relevant to current circumstances in this pandemic. In this article, the authors conclude that, according to the principle of distributive justice that prevails in cases of pandemic, a mechanical ventilator can be considered a divisible resource and be shared by at least two patients at the same time.

Apart from the physiological and clinical considerations that have already demonstrated that ventilating two patients with a single ventilator is feasible,,$^{2-4}$ we have the following comments:

Medicine, laws and social values are not static and, therefore, reexamining the ethical principles of medicine and their application in new or extraordinary circumstances (such as this pandemic) is a mandatory exercise for society, and in particular for doctors. We consider that doubts do not end here: When is it divisible and when not? What other previously considered indivisible procedures or equipment can be adapted to be shared between patients?
Knowledge, skills and attitudes that are of great value to society and that are expressed through professionalism are deposited in our profession. All this baggage should not be limited only to patient disease individually, but also reach society and its circumstances; in other words, patient-focused traditional medicine should be reconciled with public health, recognizing the true dimension of medical practice. It is essential to envision future scenarios with this focus and in these times of uncertainty or scarcity of resources. The work that motivated this letter is an example of how research impacts medical practice and ethics in extraordinary situations.

\section{References}

1. Vázquez-de Anda G, Ruíz-de Chávez M, Pérez-Castañeda A, Vázquez-Moreno P, Dávila-Fernández JC, Delaye-Aguilar MG. El ventilador mecánico como recurso divisible ante la pandemia de Covid-19. Gac Med Mex. 2020;156:306-310

2. Beitler JR, Mittel AM, Kallet R, Kacmarek R, Hess D, Branson R, et al. Ventilator sharing during an acute shortage caused by COVID-19 pandemic. Am J Respir Crit Care Med. 2020;202:600-604.

3. Castañón-González JA, Camacho-Juárez S, Gorordo-Delsol LA, Garduño-López J, Pérez-Nieto O, Amezcua-Gutiérrez MA, et al. Ventilación mecánica simultánea con un solo ventilador a varios pacientes. Gac Med Mex. 2020;156:250-253.

4. Castañón-González JA, Camacho-Juárez S, Gorordo-Delsol LA, Garduño-López J, Pérez-Nieto O, Amezcua-Gutiérrez MA, et al. Factibilidad de la ventilación mecánica compartida. Gac Med Mex. 2020;156:368. 